\title{
USO DE SUBSTRATOS LIGNOCELULÓSICOS PARA CULTIVO DE Cryptococcus laurentti VISANDO A PRODUÇÃO DE ENDO XILANASE
}

\author{
B. A. M. PERRET ${ }^{1}$, D.M. OTERO ${ }^{1}$, L.M. TEIXEIRA ${ }^{1}$ e S. J. KALIL ${ }^{1}$ \\ ${ }^{1}$ Universidade Federal do Rio Grande, Escola de Química e Alimentos \\ E-mail para contato: deborah.m.otero@gmail.com.br
}

\begin{abstract}
RESUMO - O objetivo deste trabalho foi investigar a produção de xilanases utilizando substratos agroindustriais ricos em hemicelulose como fonte de xilana nos meios de cultivo. Para seu desenvolvimento foi utilizada a levedura Cryptococcus laurentti, previamente isolada, e cinco substratos agroindustriais (casca de arroz, casca de aveia, tegumento de soja, farelo de arroz desengordurado e sabugo de milho) com e sem pré-tratamento alcalino. Para inserção dos co- produtos ao meio de cultivo os mesmos foram moídos com tamanho entre 0,335 e $0,300 \mathrm{~mm}$ e utilizados na concentração de $2 \%$. Os cultivos foram mantidos durante 96 horas e em intervalos de 24 horas foram retiradas alíquotas para determinação do $\mathrm{pH}$ e atividade enzimática. Para fins de comparação foi realizado um cultivo da levedura em meio complexo a base de xilana onde a máxima atividade foi de $8,4 \mathrm{U} \cdot \mathrm{mL}^{-1}$ em 48 horas de cultivo. Dentre os cooprodutos utilizados o que mais se destacou frente a produção da enzima foi o farelo de arroz desengordurado pré-tratado, o qual atingiu uma atividade máxima de 8,7 U.mL-1 em pH 7,3.
\end{abstract}

\section{INTRODUÇÃO}

O uso de resíduos agrícolas como substrato em bioprocessos, além de possibilitar a viabilidade econômica, auxilia a resolver os problemas ambientais decorrentes do seu acúmulo na natureza. Esses resíduos gerados podem ser usados como substrato para crescimento celular ou em processos de fermentação para obtenção de bioprodutos (Pandey et al., 1999; Pandey, 2002), como enzimas.

As enzimas xilanases vêm ganhando destaque, haja vista sua ampla aplicação na indústria têxtil, alimentícia, farmacêutica e na conversão da biomassa lignocelulósica. A produção industrial de enzimas é, geralmente, limitada pelo custo do substrato utilizado para o cultivo dos micro-organismos. Para tornar sua produção mais competitiva, a utilização de substratos de baixo custo e facilmente disponíveis deve ser explorada, além de avanços tecnológicos e da busca por novos micro-organismos (Tengerdy; Szakacs, 2003; Polizelli et al., 2005; Sukumaran, 2009).

A endo $\beta-1,4$ xilanase (EC 3.2.1.8) forma o principal grupo de enzimas envolvidas na degradação da xilana. Trata-se de uma endo-enzima que degrada, aleatoriamente, a cadeia principal de xilana, liberando xilo-oligossacarídeos (Haltrich et al., 1996 ; Kulkarni et al., 
1999). Com base no exposto, o objetivo deste trabalho foi cultivar a levedura Cryptococcus laurentti em meios com diferentes cooprodutos agroindustriais com e sem pré-tratamento, visando a produção de enzimas endo xilanase.

\section{MATERIAL E MÉTODOS}

\subsection{Micro-organismo}

A levedura Cryptococcus laurentii foi isolada e selecionada em estudos anteriores por Otero (2012). A cultura foi mantida em ágar inclinado contendo GYMP (20 g.L $\mathrm{L}^{-1}$ glicose; 5 g.L $\mathrm{L}^{-1}$ extrato de levedura; 10 g.L.- extrato de malte; 2 g.L $\mathrm{L}^{-1} \mathrm{KH}_{2} \mathrm{PO}_{4}$ e 20 g.L.-1 ágar) a $4{ }^{\circ} \mathrm{C}$ (Maugeri, 2007).

\subsection{Substratos}

Foram utilizados farelo de arroz desengordurado, casca de arroz, sabugo de milho, casca de aveia e tegumento de soja como fontes de xilana para a produção enzimática. Os substratos foram obtidos de industriais locais e cada um deles foi seco, moído em moinho de facas e submetidos ao peneiramento para obter partículas com tamanho entre $0,355 \mathrm{~mm}$ e $0,3 \mathrm{~mm}$.

\subsection{Pré-tratamento dos substratos lignocelulósicos}

Cada substrato, com tamanho de partícula já padronizado, foi tratado com hidróxido de sódio $4 \%$ durante $30 \mathrm{~min}$ a $40^{\circ} \mathrm{C}$ sob agitação. Após os substratos foram lavados com água destilada até o desaparecimento da coloração amarela e neutralização (Gokhale and Bastwade, 1997).

\subsection{Preparo do inóculo para produção de xilanase}

O inóculo foi crescido em $150 \mathrm{~mL}$ de meio composto por: 10,0 g. $\mathrm{L}^{-1}$ xilana de Beechwood, 3,0 g.L extrato de levedura, 7,0 g.L $\mathrm{L}^{-1} \quad \mathrm{KH}_{2} \mathrm{PO}_{4}, \quad 2,0$ g.L. $\mathrm{K}_{2} \mathrm{HPO}_{4}$, 0,1 g.L.- $\mathrm{MgSO}_{4} .7 \mathrm{H}_{2} \mathrm{O}, 1,0$ g.L. $\left(\mathrm{NH}_{4}\right) \mathrm{SO}_{4}, 5,0$ g.L $\mathrm{L}^{-1}$ peptona e $\mathrm{pH}$ 6.0), a $30^{\circ} \mathrm{C}$ e $150 \mathrm{rpm}$ durante $24 \mathrm{~h}$ (Lopes, 2011).

\subsection{Produção de xilanase em cultivos submersos usando substratos industriais}

As culturas obtidas a partir do inóculo foram transferidas para frascos erlenmeyers com capacidade de $500 \mathrm{~mL}$ contendo $150 \mathrm{~mL}$ do mesmo meio de cultivo sendo a xilana substituída por 20,0 g.L. $\mathrm{L}^{-1}$ de cada substrato agroindustrial (sabugo de milho, farelo de arroz desengordurado, casca de aveia, casca de arroz e tegumento de soja). Os cultivos foram iniciados com suspensão celular de $10^{7}$ células. $\mathrm{mL}^{-1}$ e incubados em agitador rotatório orbital a $30^{\circ} \mathrm{C}$ e $150 \mathrm{rpm}$. Amostras foram coletadas ao longo de 96 horas e centrifugadas a $6.000 x \mathrm{~g} \mathrm{a} 4{ }^{\circ} \mathrm{C}$ por $10 \mathrm{~min}$, sendo o sobrenadante livre de células usado para as determinações de $\mathrm{pH}$ e atividades enzimáticas. Os experimentos foram realizados em triplicata e os resultados descritos como a média dos três ensaios. 


\subsection{Determinação enzimática}

Atividade de endo-xilanase foi determinada conforme descrito por Bailey et al. (1992) usando $1 \%$ de xilana de Beechwood, sendo os açúcares redutores qunatificados usando método DNS (Miller, 1959), onde a xilose liberada foi medida em espectrofotômetro a 540 nm. Uma unidade de atividade enzimática é definida como a quantidade de enzima necessária para liberar um $\mu \mathrm{mol}$ de xilose por $\mathrm{mL}$ por minuto sob as condições descritas.

\section{RESULTADOS E DISCUSSÕES}

Através da Figura 1 é possível observar que dentre os cooprodutos estudados, os que ofereceram as melhores condições de crescimento para a levedura e consequentemente maior atividade enzimática, mesmo sem a remoção da lignina, foram o farelo de arroz e a casca de aveia, visto que as atividades foram de 7,5 U.mL e 5,3 U.mL $\mathrm{mL}^{-1}$ respectivamente. Essas máximas atividades foram alcançadas em 24 horas de cultivo onde o $\mathrm{pH}$ foi de 7,4 e 7,2 respectivamente. A mínima atividade foi observada nos cultivos utilizando sabugo de milho como fonte de xilana. A máxima atividade encontrada neste substrato foi de 1,6 U.mL $\mathrm{mL}^{-1} \mathrm{em}$ $\mathrm{pH} 7,6$. Para fins comparativos, foi realizado um cultivo em meio a base de xilana usando a levedura para produção enzimática onde a atividade alcançada foi de $8,4 \mathrm{U} \cdot \mathrm{mL}^{-1} \mathrm{em} 48$ horas de cultivo.

Figura 1: Acompanhamento da produção de endo xilanase pela levedura Cryptococcus

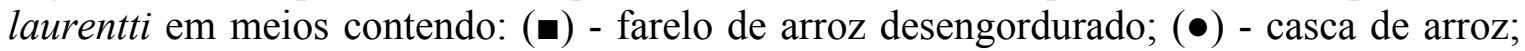
$(\times)$ - sabugo de milho; $(\circ)$ - casca de aveia e $(\boldsymbol{\nabla})$ - tegumento de soja sem tratamento.

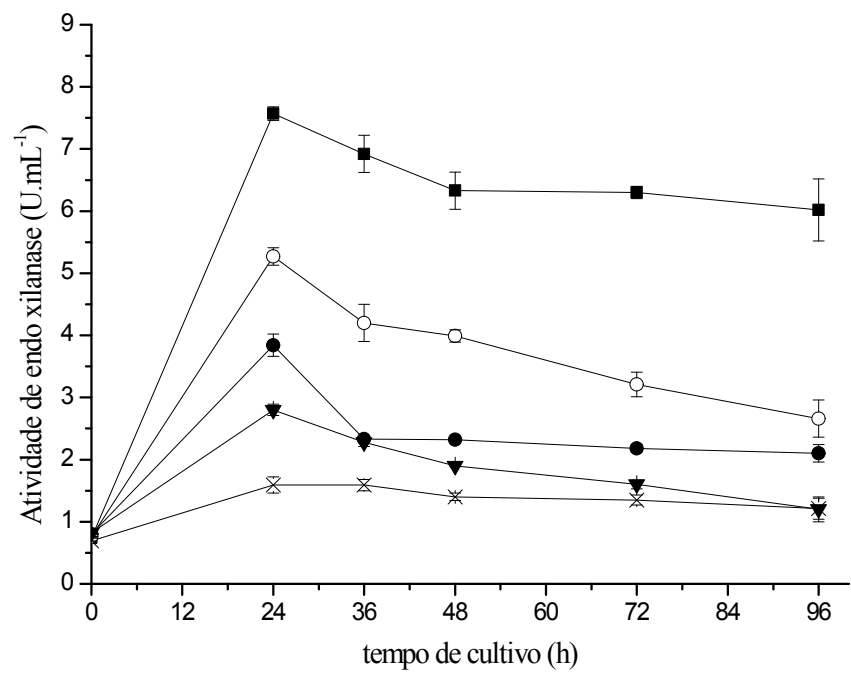

Os constituintes dos cooprodutos (hemicelulose, lignina, celulose) geralmente encontram-se associados dificultando assim o ataque de agentes químicos, enzimáticos ou microbianos, os quais não possuem a capacidade de assimilar agregados tão grandes e diante 
desse fato os cooprodutos passaram por pré-tratamento alcalino $(\mathrm{NaOH} 4 \%)$. As reações iniciais são as de solvatação e saponificação, ocorrendo degradação química e ionização dos grupos hidroxila, provocando um estado de inchaço da biomassa e tornando-a mais acessível para as enzimas e micro-organismos. Esse procedimento facilita a acessibilidade aos carboidratos, além de promover a quebra da lignina e rompimento da estrutura cristalina da celulose.

Os resultados obtidos nos cultivos foram satisfatórios uma vez que a atividade de endo xilanase, obtida em meio contendo farelo de arroz tratado, foi de 8,7 U.mL $\mathrm{mL}^{-1}$ em 48 horas de cultivo em $\mathrm{pH} 7,3$, seguida pela atividade enzimática em casca de aveia, a qual foi de 5,5 U.mL $\mathrm{mL}^{-1} \mathrm{em}$ tempo igual (48 horas) e pH 7,5. Observa-se que mesmo após o pré-tratamento o sabugo de milho não apresentou alta atividade $\left(1,6 \mathrm{U} \cdot \mathrm{mL}^{-1}\right)$, o que indica que este cooproduto não oferece condições suficientes para a produção enzimática elevada. $O$ acompanhamento das atividades enzimáticas nos diferentes cooprodutos usados ao longo de 96 horas de cultivo encontra-se na Figura 2.

Figura 2: Acompanhamento da produção de endo xilanase pela levedura Cryptococcus laurentti em meios contendo: (曰) - farelo de arroz desengordurado; (•) - casca de arroz; $(\times)$ - sabugo de milho; (०) - casca de aveia e ( $\mathbf{\nabla})$ - tegumento de soja com prétratamento alcalino.

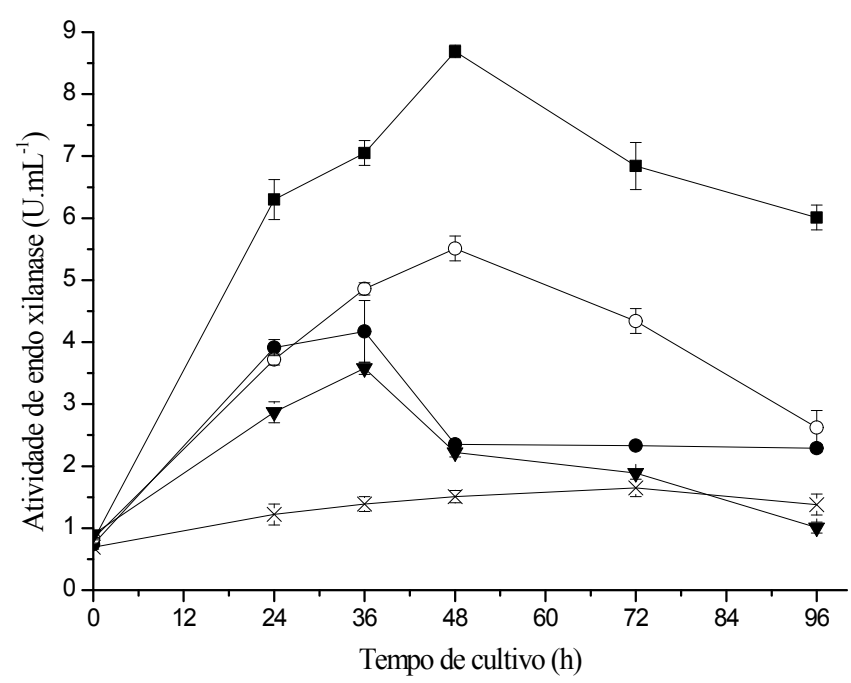

Segundo Domene (1996), o farelo de arroz integral destaca-se como uma boa fonte de vitaminas do complexo B e E, sendo pobre em vitamina A e ausente de vitamina $D$, o nível de proteína bruta do farelo varia entre 10 a $15 \%$, sendo superior à proteína do trigo e do milho. Com relação à sua composição mineral, este é extremamente rico em fósforo e manganês, além dos níveis de cobre, ferro e zinco e por isso se mostra uma boa fonte para crescimento microbiano (Conte, 2000). 
Harada (2008) utilizou farelo de arroz para produção de xilanases, a hemicelulose do farelo foi utilizada como substrato e única fonte de carbono para Paenibacillus $s p$, o qual foi capaz de produziu xilanases (valores não apresentados).

As diferenças nos níveis de produção observados entre os resíduos agroindustriais podem estar relacionadas às diferenças em sua composição, bem como na acessibilidade dos substratos pela linhagem (Stroparo et al., 2012). Os materiais lignocelulósicos são formados por uma rede altamente complexa de polissacarídeos (celulose, hemicelulose e pectina) e de macromoléculas aromáticas (lignina) os quais diferem uns dos outros frente ao conteúdo e diferem entre sí devido a espécie, época do ano, idade da planta, etc.(Beg et al, 2001).

Através dos cultivos realizados com Cryptococcus laurentti pode-se observar que o substrato que mais se destacou para a produção de endo xilanases foi o farelo de arroz, alcançando suas máximas atividade de 7,5 U.mL ${ }^{-1}$ quando o cooproduto não foi tratado e $8,7 \mathrm{U} \cdot \mathrm{mL}^{-1}$ quando cooproduto recebeu tratamento alcalino prévio. Acredita-se que esse procedimento permitiu a disponibilidade dos componentes que constituem a matéria prima frente ao ataque microbiano, tornando assim os compostos acessíveis ao processo de transformação.

Assim sendo considera-se que o farelo de arroz desengordurado apresenta uma viabilidade interessante frente ao seu uso como fonte de xilana para a produção enzimática além de ser um produto com custo inferior quando comparado a xilana comercial. Desta maneira, o aproveitamento de resíduos lignocelulósicos agroindustriais como matérias-primas para processos microbianos industriais é uma alternativa econômica e ambientalmente viável, pois irá agregar valor a esses resíduos podendo reduzir um problema ambiental causado pelo seu acúmulo excessivo.

\section{CONCLUSÕES}

A atividade de endo xilanase produzida pela levedura estudada (Cryptococcus laurentti) apresentou resultados muito satisfatórios quando cultivadas em meios contendo cooprodutos como fonte de xilana, principalmente o farelo de arroz desengordurado, uma vez que a atividade máxima encontrada no cooproduto foi igual ao meio com xilana purificada (8,7 U.mL $\mathrm{mL}^{-1}$ ). Deve-se levar em consideração que a fonte de xilana disponível no cooproduto não é purificada, apenas tratada com solução de $\mathrm{NaOH} 4 \%$ e por se tratar de um cooproduto da indústria de óleo de arroz, seu desempenho foi muito positivo frente a produção de endo xilanase.

\section{AGRADECIMENTOS}

Os autores agradecem ao Conselho Nacional de Desenvolvimento Cientifico e Tecnológico (CNPq), a Fundação de Amparo à Pesquisa do Estado do Rio Grande do Sul (FAPERGS) e a Coordenação de Aperfeiçoamento de Pessoal de Nível Superior (CAPES) pelo suporte financeiro desta pesquisa. 


\section{REFERÊNCIAS}

BAILEY MJ, BIELY P, POUTNEN K. Interlaboratory testing of methodos for assay of xylanase activity. J Biotechnol. v 23: p. 257-270, 1992.

CONTE, A. J. Valor nutritivo do farelo de arroz integral em rações para frangos de corte, suplementado com fitase e xilanase. Tese (Doutorado). Universidade Federal de Lavras, $164 \mathrm{f}, 2000$.

DOMENE, S.M.A. Estudo do valor nutritivo mineral do farelo de arroz. Utilização do zinco, ferro, cobre e cálcio pelo rato em crescimento. Tese (Doutorado). Universidade de Campinas, 104 f, 1996.

HALTRICH, D. ; NIDETZKY, B. ; KULBE, K.D. ; STEINER, W. ; ZUPANCIC, S. Production of fungal xylanases. Bioresour. Technol., v 58, p.137 - 161, 1996.

HARADA, M.H. et al. Paenibacillus sp. Strain HC1 xylanases responsible for degradation of rice bran hemicellulose. Microbiol. Res., v.163, p.293-298, 2008.

KULKARNI, N.; SHENDYE, A. RAO, M. Molecular and biotechnological aspects of xylanases. FEMS Microbiol. Rev., v. 23, p. 411-456. 1999.

LOPES, F.; MOTTA, F.; ANDRADE, C.C.P.; RODRIGUES, M.I.; MAUGERI-FILHO F. Thermo-stable xylanases from non-conventional yeasts. J. Microbiol. Biochem. Technol.,v 3, p 36-42, 2011.

MAUGERI, F.; HERNALSTEENS, S. Screening of yeast strains for transfructosylating activity. J. Mol. Catal. B. Enzym. v 49, p 43-49, 2007.

OTERO, D. M.; TEIXEIRA, L. M.; SANZO, A. V.; KALIL, S. J. Selección de levaduras productoras de enzimas xilanoliticas. In: IV Congreso Internacional de Ciencia y Tecnologia de los Alimentos, 2012.

PANDEY, A.; RADHAKRISHNAN, S. Packed - bed Column bioreactor for Production of Enzyme. Enz. Microbiol. Techn. v. 14, p. 486- 488, 1992.

PANDEY, A. Solid-state fermentation. Biochem. Eng. J., v. 3636, p. 1- 4, 2002.

POLIZELLI, M. L. T. M; RIZZATTI, A.C.S; MONTI, R.; TERENZI, H.F.; JORGE, J. A.; AMORIM, D.S. Xylanases from fungi: properties and industrial applications. Appl Microbiol. Biotechnol. v. 67, p. 577-591, 2005.

SUKUMARAN, R. K.; SINGHANIA,R.R.; MATHEW, G.M.; PANDEY, A. Cellulase prodution using biomass feed stok and its aplication in lignocellulose saccharification for bio-ethanol prodution. Ren. Ener., v. 34, p. 421-424, 2009. 
STROPARO, E.C.; Beitel, S. M.; Resende, J.T.V.; Knob, A. Seleção de fungos filamentosos e de resíduos agroindustriais para a produção de enzimas de interesse biotecnológico. Semina: Ciências Agrárias, Londrina, v. 33, p. 2267-2278, 2012.

TENGERDY, R. P.; SZAKACS, G. Bioconversion of lignocellulose in solid substrate fermentation. Biochem. Eng. J., v. 13, p. 169-179, 2003. 